\title{
Comparison of Biota Species Sensitivity Distributions to Nonylphenol in China and the United States
}

\author{
Liangmao ZHANG \\ College of Resources and Environment \\ Huazhong Agricultural University \\ Wuhan 430070, China \\ e-mail: 269081279@qq.com
}

\author{
Caidi WEI \\ College of Resources and Environment \\ Huazhong Agricultural University \\ Wuhan 430070, China \\ e-mail: 1541900681@qq.com,
}

\author{
Mingwei SONG \\ College of Resources and Environment \\ Huazhong Agricultural University \\ Wuhan 430070, China \\ e-mail:songmw@mail.hzau.edu.cn
}

\begin{abstract}
Based on the acute toxicity data for aquatic organisms from China and the United States, species sensitivity distributions (SSDs) were developed to derive to $\mathrm{HC}_{5}$ (the Hazardous Concentration for $5 \%$ of the species). Sensitivity to NP in taxa of vertebrates, invertebrates and plants were compared separately between China and USA. The results show that: (1) The SSD model which constructed by LogLogistic distribution is robust; (2) Under the $95 \%$ protection level, the sensitivity of all aquatic organisms both in China and the United States was in the order: vertebrates >invertebrates and plants; (3) Based on the $\mathrm{HC}_{5}$ value for short-term exposure to NP, vertebrates are more sensitive in China than in the United States when the sensitivity of invertebrates and plants is similar both in China and the United States; (4) The sensitivity distributions derived for all species in the United States is $7.65 \mu \mathrm{g} / \mathrm{L}$ higher than that in China. Therefore, in determining the water quality criteria based on the sensitivities of all species, we should also consider the influence of SSD of individual groups.
\end{abstract}

Keywords-Nonylphenol; Species Sensitivity Distribution (SSD); Hazardous Concentration for $5 \%$ of the Species $\left(H_{5}\right)$; water quality criteria

\section{INTRODUCTION}

Nonylphenol (NP) is a typical endocrine disruptor with carcinogenic, teratogenic and mutagenic, which can affect the biological endocrine activity and normal growth[1]. With the rapid development of industry and social economy, a lot of NP eventually released through various channels into the environment, resulting in an inevitable impact on the structure and function of ecosystems[2]. However, the water quality criteria (WQC) of NP have not been established in China, to develop a national water quality criteria system of NP in China is an urgent task [3].

The species sensitivity distributions is based on the single species test to assess the ecological risk and this method has been widely used in the derivation of environmental quality criteria in the world[4]. In this study, the species sensitivity distribution model of different species to NP in aquatic ecosystem were constructed by acute toxicity in China and the United States, and to analysis the difference of species sensitivity between the two countries. And hoping to provide theoretical basis and method support for the environmental protection in China.

\section{MATERIALS AND METHODS}

\section{A. Acquisition of Toxicity Data}

The toxicity data (Table I) of NP used in this study were collected mainly from the existing literature and USA EPA toxicity database, And the toxicological endpoints $\mathrm{LC}_{50}$ or $\mathrm{EC}_{50}(48 \mathrm{~h}$ for invertebrates and $96 \mathrm{~h}$ for vertebrates and algae, respectively) is selected to construct SSD model.

In this research, the acute toxicity of NP to aquatic organisms in North America has been determined for 31 species, 23 families and 4 phyla, which including algae (green alga), mollusca, crustacea, fish (mainly for Salmonidae) and amphibian. The acute toxicity data in China covered 31 species, 21 families and 7 phyla, which including algae (green alga, diatom and chrysophyta), mollusca, crustacea, fish (mainly for Cyprinidae).

TABLE I. ThE ACUTE ToXicity DATA OF NP IN CHINA AND UsA

\begin{tabular}{|c|c|c|c|}
\hline Country & Type & $\begin{array}{l}\text { Sample } \\
\text { size }\end{array}$ & Range of values $/\left(\mu \mathrm{g} \mathrm{L}^{-1}\right)$ \\
\hline \multirow{4}{*}{ China } & Arthropoda & 9 & $35-278$ \\
\hline & $\begin{array}{l}\text { Non-arthropod invertebrates } \\
\text { invertebrates }\end{array}$ & 5 & $50-541$ \\
\hline & Chordate & 12 & $135-9740$ \\
\hline & Plants & 5 & $40-1380$ \\
\hline \multirow{4}{*}{ USA } & Arthropoda & 8 & $51.05-300$ \\
\hline & Non-arthropod invertebrates & 2 & $37.9-100$ \\
\hline & Chordate & 20 & $17-900$ \\
\hline & Plants & 1 & 410 \\
\hline
\end{tabular}




\section{B. Species sensitivity Distribution Model}

\section{1)Establishment of SSD model}

Log-Logistic distribution (Eq.(1)) was used to fit the data of toxicity data in this study.

$$
Y=\frac{1}{1+e^{-(X-\alpha) / \beta}}
$$

Where $\mathrm{Y}$ refers to the cumulative probability; $\mathrm{X}$ refers to the value of the logarithm transform of toxicity data; $\alpha$ and $\beta$ represent parameters of the function. The parameters of the function values are determined through the maximum likelihood method[5] to the SSD curve. In order to comprehensive evaluate the quality of Log-Logistic model, the parameter Bootstrap method[6]is used to analyze the uncertainty of model parameters and Kolmogorov-Smirnov test[7] was used to quantitative evaluation the results of the model in this study. Based on this model, to further analyze the difference sensitivity of species between USA and China, this paper investigates the difference distribution of it by independent sample T-test and the model is calculated by a mathematical software R 3.2.4. According to the toxicity data from table I, we can construct the model of LogLogistic distribution and obtain the SSD curve (Figure 1).

\section{III.RESULTS AND DISCUSSION}

\section{A. Statistical Analysis}

From the test results (Table II), the $\mathrm{P}$ values of the models are more than 0.05 , so it doesn't reject the original hypothesis and the data is consistent with the hypothetical Log-Logistic model. The theoretical values of the model parameters fall within the $95 \%$ confidence interval that obtained from the sample of Bootstrap parameters, which indicates the model has good robustness. There is no significant difference between the $95 \%$ confidence interval of the model parameters and the $95 \%$ confidence interval of the Bootstrap parameters estimation and the construction of the SSD model is robust.

TABLE II. THE RESULTS OF STATISTICS

\begin{tabular}{|c|c|c|c|c|c|}
\hline \multirow{2}{*}{ Type } & \multirow{2}{*}{ Country } & \multicolumn{2}{|l|}{$\mathrm{HC}_{5}$} & \multirow{2}{*}{$\begin{array}{l}\text { Goodness-of-fit of } \\
\text { the SSD } \\
\text { K-S (P value) }\end{array}$} & \multirow{2}{*}{$\begin{array}{l}\begin{array}{l}\text { Difference } \\
\text { significance test }\end{array} \\
\text { T-test (P value) }\end{array}$} \\
\hline & & $\begin{array}{l}\text { Theoretical values with } \\
95 \% \text { CI }\end{array}$ & Estimated by Bootstrap & & \\
\hline \multirow{2}{*}{$\begin{array}{l}\text { Invertebrates } \\
\text { and plants }\end{array}$} & China & $\begin{array}{l}31.8 \\
(13.06-77.26) \\
\end{array}$ & 33.65 & 0.9016 & \multirow{2}{*}{0.099} \\
\hline & USA & $\begin{array}{l}27.4 \\
(11.94-62.8) \\
\end{array}$ & 29.5 & 0.8035 & \\
\hline \multirow{2}{*}{ Vertebrates } & China & $\begin{array}{l}42.8 \\
(11.46-159.6)\end{array}$ & 48.3 & 0.7872 & \multirow{2}{*}{0.0272} \\
\hline & USA & $\begin{array}{l}54.7 \\
(31.12-96.16) \\
\end{array}$ & 57.01 & 0.963 & \\
\hline \multirow{2}{*}{ All species } & China & $\begin{array}{l}33.27 \\
(15.45-71.61) \\
\end{array}$ & 34.83 & 0.9112 & \multirow{2}{*}{0.0191} \\
\hline & USA & $\begin{array}{l}40.92 \\
(24.66-67.92)\end{array}$ & 41.97 & 0.9876 & \\
\hline \multirow{3}{*}{ Type } & \multirow{3}{*}{ Country } & \multicolumn{4}{|c|}{ Uncertainty analysis of model parameters } \\
\hline & & Theoretical values $(95 \%$ & & Bootstrap $(95 \%$ & \\
\hline & & $\alpha$ & $\beta$ & $\alpha$ & $\beta$ \\
\hline \multirow{2}{*}{$\begin{array}{l}\text { Invertebrates } \\
\text { and plants }\end{array}$} & China & $\begin{array}{l}2.34 \\
(2.102-2.573) \\
\end{array}$ & $\begin{array}{l}0.2845 \\
(0.202-0.423)\end{array}$ & $\begin{array}{l}2.341 \\
(2.127-2.558) \\
\end{array}$ & $\begin{array}{l}0.271 \\
(0.178-0.391) \\
\end{array}$ \\
\hline & USA & $\begin{array}{l}2.057 \\
(0.137-0.355)\end{array}$ & $\begin{array}{l}0.2102 \\
(1.824-2.297)\end{array}$ & $\begin{array}{l}2.057 \\
(1.833-2.276)\end{array}$ & $\begin{array}{l}0.195 \\
(0.108-0.313)\end{array}$ \\
\hline \multirow{2}{*}{ Vertebrates } & China & $\begin{array}{l}2.688 \\
(2.328-3.096) \\
\end{array}$ & $\begin{array}{l}0.3591 \\
(0.232-0.603) \\
\end{array}$ & $\begin{array}{l}2.6879 \\
(2.334-3.050) \\
\end{array}$ & $\begin{array}{l}0.3339 \\
(0.192-0.524) \\
\end{array}$ \\
\hline & USA & $\begin{array}{l}2.283 \\
(2.139-2.429)\end{array}$ & $\begin{array}{l}0.1851 \\
(0.130-0.278)\end{array}$ & $\begin{array}{l}2.2822 \\
(2.141-2.422)\end{array}$ & $\begin{array}{l}0.1784 \\
(0.118-0.253)\end{array}$ \\
\hline \multirow{2}{*}{ All species } & China & $\begin{array}{l}2.214 \\
(2.084-2.341)\end{array}$ & $\begin{array}{l}0.2043 \\
(0.154-0.279)\end{array}$ & $\begin{array}{l}2.2154 \\
(2.088-2.339)\end{array}$ & $\begin{array}{l}0.1987 \\
(0.145-0.263)\end{array}$ \\
\hline & USA & $\begin{array}{l}2.214 \\
(2.084-2.341)\end{array}$ & $\begin{array}{l}0.2043 \\
(0.154-0.279)\end{array}$ & $\begin{array}{l}2.2144 \\
(2.088-2.339)\end{array}$ & $\begin{array}{l}0.1985 \\
(0.145-0.265)\end{array}$ \\
\hline
\end{tabular}




\section{B. Comparison of Biota Species Sensitivity Distributions to $N P$}

In this study, 10 invertebrates and 16 vertebrates in China and 10 invertebrates and 20 vertebrates in USA were selected to calculate the $\mathrm{HC}_{5}$ of all species and the results (Table II) shown that $33.27 \mu \mathrm{g} / \mathrm{L}$ in China and $40.92 \mu \mathrm{g} / \mathrm{L}$ in USA, which is about $7.65 \mu \mathrm{g} / \mathrm{L}$ between them. Generally speaking, the detoxification mechanism of higher organisms is better than that of lower organisms and the sensitivity of lower invertebrates to NP is higher than that of vertebrates [8]. And the proportion of vertebrate species in the United States $(65 \%)$ is greater than China (52\%), which may be one of the reasons why the $\mathrm{HC}_{5}$ of the United States is more than China.

Due to the tolerances of vertebrates is generally higher than invertebrates, so all species are classified into vertebrates and invertebrates for further analysis in this study. As shown in the table III, the $\mathrm{HC}_{5}$ of vertebrates in China is $42.8 \mu \mathrm{g} / \mathrm{L}$ and $54.70 \mu \mathrm{g} / \mathrm{L}$ in USA. According to the toxicity data and distribution curve, 18 of the 20 vertebrates toxic values selected from the United States were in the range of 110 to $900 \mu \mathrm{g} / \mathrm{L}$, and the rest of which were Menidia beryllina $(70 \mu \mathrm{g} / \mathrm{L})$ and Pleuronectes americanus $(17 \mu \mathrm{g} / \mathrm{L})$ which located at the bottom of the distribution curve, but the toxicity data of vertebrates from China had a wide distribution in the curve with a range of 135 to $9740 \mu \mathrm{g} / \mathrm{L}$. Almost in the whole concentration range (Figure 1), the vertebrates in China is more sensitive than those in USA except for there has a small overlay region at the top of the curve, the acute toxicity data of vertebrates in USA in all curve is more concentrate than China. And the variance analysis is also indicated that the significant differences $(\mathrm{P}<0.05)$ were observed between sensitivity distributions derived for vertebrates in China and the United States. For invertebrates and plants, no significant differences $(\mathrm{P}>0.05)$ were observed between China and USA in this study, and the $\mathrm{HC}_{5}$ of invertebrates and plants in China is $31.8 \mu \mathrm{g} / \mathrm{L}$ and $27.4 \mu \mathrm{g} / \mathrm{L}$ in USA which indicated that the sensitivity to NP of invertebrates and plants in China and USA is similar. According to the SSD curve (Figure 1), most of arthropods from China in this research is at the bottom of the SSD curve and appeared higher sensitivity of NP and the distribution of invertebrates and plants in China.
Through this study we can find that species from the water ecosystem in China were more sensitive to NP than that in the United States. We couldn't manage the risk of NP in Chinese water systems entirely adopted the ecological risk threshold for the derivation of freshwater biological species in the United States, or it would make all species in the freshwater biota of China out of protection.

\section{IV.CONCLUSIONS}

The SSD model of aquatic organisms from China and the United States to NP is robust, which was constructed by log logistic distribution. Under the $95 \%$ protection level, the sensitivity of various aquatic organisms in China and the United States to NP was in the order: vertebrate > invertebrates and plants, the sensitivity of invertebrates and plants in China was comparable to that in the United States, and the vertebrates were less sensitive in China than in the United States. The $\mathrm{HC}_{5}$ of all species in the United States was $7.65 \mu \mathrm{g} / \mathrm{L}$ higher than that in China and the ecological risk threshold for the derivation of aquatic organism in the United States may cause all species in China out of protection.

\section{REFERENCES}

[1] Radix, P., et al., Reproduction disturbances of Brachionus calyciflorus (rotifer) for the screening of environmental endocrine disrupters. Chemosphere, 2002. 47(10): p. 1097-1101.

[2] Soares, A., et al., Nonylphenol in the environment: A critical review on occurrence, fate, toxicity and treatment in wastewaters. Environment International, 2008. 34(7): p. 1033-1049.

[3] Wu, F., et al., China embarking on development of its own national water quality criteria system. Environmental science \& technology, 2010. 44(21): p. 7992-7993.

[4] Posthuma, L., G.W. Suter II, and T.P. Traas, Species sensitivity distributions in ecotoxicology. 2001: CRC press.

[5] Murshudov, G.N., A.A. Vagin, and E.J. Dodson, Refinement of Macromolecular Structures by the Maximum-Likelihood Method. Acta Crystallographica, 1997. 53(Pt 3): p. 240-55.

[6] Danielsson, J., et al., Using a Bootstrap Method to Choose the Sample Fraction in Tail Index Estimation is. Journal of Multivariate Analysis, 2001. 76(76): p. 226-248.

[7] Lopes, R.H.C., Kolmogorov-Smirnov Test. 2005. 718-720.

[8] Wu, F.-C., L. Huixian, and F. Chenglian, The theory,methodology and case study of water quality criteria. 2012, Beijing: Science Press (In Chinese)
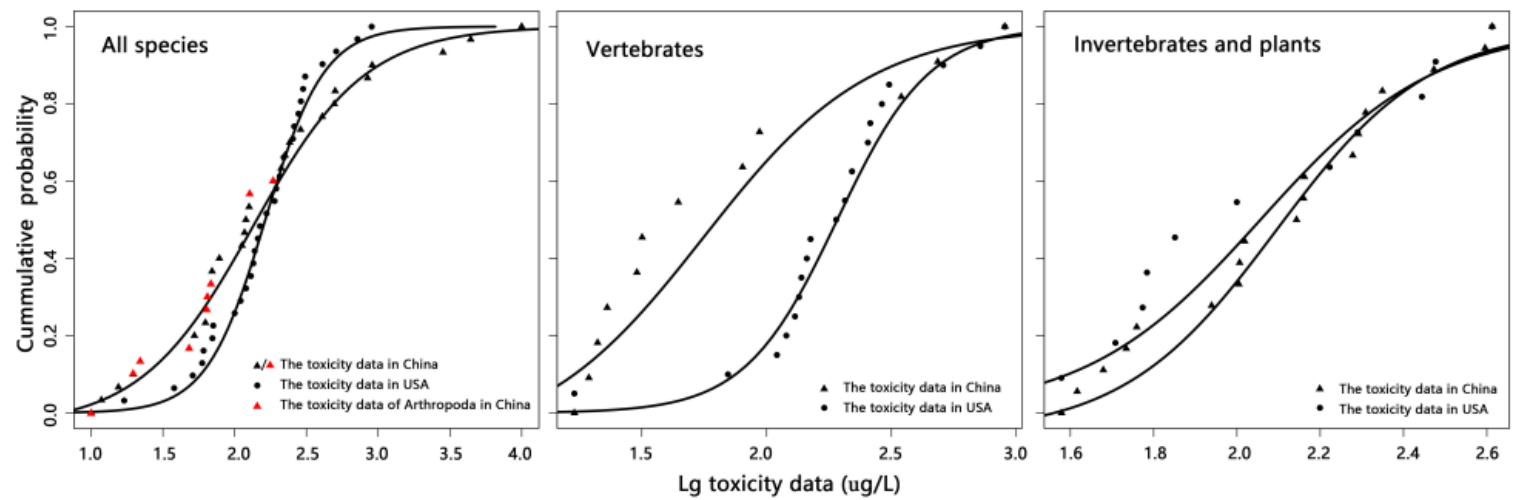

Figure 1. The species sensitivity distribution of NP based on all species, vertebrates, invertebrates and plants toxicity data. 